\title{
Research of the Blended Teaching Method Under SPOC
}

\section{_ A Case study of Business Intelligence Curriculum}

\author{
Jian Chen * \\ School of Economic and Management Shanghai Polytechnic University, China \\ "Corresponding author. Email:chenjian@sspu.edu.cn
}

\begin{abstract}
Blended teaching method develops rapidly in teaching revolution in many universities. Online teaching and studying becomes a vital component in modern education system. But, in many experiment cases, teachers find it is quite hard for each student with different background, and how to provide a effective evaluation standard. This paper provides a case study based on Business Intelligence Curriculum in Shanghai Polytechnic University. Provide the SPOC teaching method from many different aspects to verify the effectiveness.
\end{abstract}

Keywords: SPOC, E-learning, Blended teaching, E-business.

\section{INTRODUCTION}

Online Teaching provides a whole new dimension to education system. In such circumstances, Shanghai Polytechnic University offer students a Business Intelligence Curriculum for third year student. It provides splendid teaching resources and study tools for both students and teachers in this curriculum. With these new methodologies of teaching spreading into universities, like e-learning, MOOC, SPOC, we should clearly feel that information technologies improves the quality of education in some level. But it does not change the traditional way of teaching. Most of students accept what teachers teach, It is very difficult to integrate teachers, students, teaching materials and teaching medias.

In traditional way of teaching, teachers lead student, following by the path pre-set in teaching materials. Students should follow what teacher say and drag by the teaching materials on the blackboard or projects. For teachers, the advanced is obvious, that teacher can have real feedbacks from students. Students can ask teachers instantly, or can have brainstorm with classmates sitting next to each other.

But in the e-learing class, students cannot feel the tense of classroom, and without instant communicate with classmates, students may easily be distracted.
Blended Teaching Method under SPOC change the sequence of the teaching and studying. This method first let students preview the content about to study by themselves, then, in the e-learning classroom, Teachers guide and focus on the discussion to solve the problems encountered in the process of students' independent learning. How to evaluate the result students study? And how to modify the teaching objectives? This paper researches such questions and provides solutions according a case study of business intelligence curriculum

\section{SPOC INTEGRATION}

SPOC, Small Private Online Course, is a new concept following by the Harvard MOOC, SPOC mainly represents curriculums using MOOC's platform and teaching methods within university. Not like MOOC, SPOC mainly focuses on the small group of students, mainly come from same class of a university, and teachers organize offline teaching activities as blended teaching. SPOC is quite different with MOOC, because main process of a SPOC is as follow: teachers regularly update online video teaching materials, digital homework and discusses of which all marked by deadlines, according to the latest syllabus. Students, on the other hands, should watch full length of videos, finish homework, probably should take pictures of them, and join online discuss. In the online classroom, teacher mainly focuses on answering the questions and tests. 
This methodology leads teachers focus on more valuable activities, such as discuss, assignment cooperation, live communication.

On the contrast, in a traditional classroom, teachers have to set the same pace of teaching process to make sure that every student in the room can follow the process. And this process can easily be interrupt by the students who are not following or be ignored by the students who already know the according knowledge. And this is the vital defect in a traditional classroom

SPOC is a blended teaching method that combines the advantage of MOOC and fixes the defects of traditional teaching.

SPOC emphasizes three key steps: pre online studying, in class discussing, and post extension studying.

But, it also raises some questions:

How to perform differentiated teaching for different student with different progresses; How to motivate the interests and activities of students online? And finally, how to evaluate the students by online tests.

\section{THE CONSTRUCTION OF TEACHING MODE}

\subsection{Case of Business Intelligence}

Business intelligence is a core curriculum in many universities, at present, the teaching content of this course is selected from the actual situation of the students, realizing the combination of professional training objectives and curriculum training objectives, as well as the combination of the requirements of working ability in the employment position. In addition to the basic practical teaching, the team analyses the actual business data to digest the knowledge points of the theoretical teaching, and at the same time, the content of the course is task-based and project-based, combined with case analysis to ensure the vividness and consistency of the course.

\subsubsection{How to Effectively Meet the Teaching Challenges of Choosing this Course for Different Majors?}

As this course is listed as the platform course of the college for cultivation, it is an important goal of this course construction to rewrite new teaching materials and new experimental teaching contents, that is, to strive to expand the course from a professional compulsory course to a platform course of the school of economic management. Due to the different professional backgrounds of different majors in the school of economics and management, platform experiments and professional experiments for different majors are a great challenge.

\subsubsection{How to Effectively Solve the Changes Brought By the Course Content of Business Intelligence in the Big Data Environment?}

As the era of big data and massive data has come, business intelligence based on data warehouse lacks the understanding of big data, massive data, distributed storage and other concepts. This situation will help students to learn and master the latest business intelligence knowledge and the skills needed by the actual big data industry, which plays a crucial role in improving the teaching quality of this course.

\subsubsection{How to Effectively Realize the Course Content Management in the Teaching System of this Major?}

Business intelligence course is a professional basic course with strong practicality, but most of the students lack of practice on business intelligence in big data environment, such as how to extract, transform and load effective data from massive data; how to carry out corresponding data mining and data visualization and other practical contents cover more knowledge points. Therefore, the new teaching plan of this major has been adjusted, and this course has been changed from a professional elective course to a professional compulsory course, which shows that this course has reached a new height after the construction of key courses and excellent courses.

\subsubsection{How to Effectively Expand Extracurricular Teaching and Improve Students' Learning Motivation?}

Business intelligence is a comprehensive course that covers data analysis, computer technology and advanced mathematics. Students need to expand reading and review after class. How to reform teaching methods and means, make up for the lack of class hours, and improve students' learning motivation are also the key objectives of this curriculum construction.

\subsubsection{How to Effectively Solve the Shortage of Practice in the International Teaching System?}

This course is very theoretical. In 2012, the course applied for bilingual teaching and passed. It involves many professional terms and theoretical knowledge. Most of the practical courses are design, algorithm and theory application courses, and most of the course contents do not involve internationalization. Most of the students have limited practical English application ability in the related work of business intelligence. 
Subjectively, they think that business intelligence is only a course of algorithm or data analysis. Cross border e-commerce has been included in the teaching program of this major in 2015. If there is no practical international operation experience, the students of this major will be in a very passive situation.

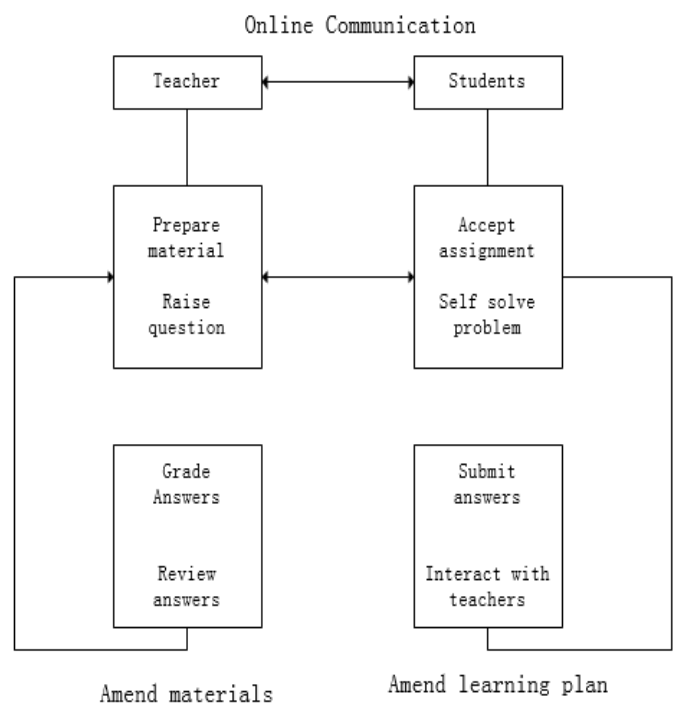

Figure 1 Teaching process

\subsection{Improvement of Teaching Methods and Implements}

\subsubsection{Teaching Methods}

This course will determine the teaching concept of intensive speaking, more discussion, more practice, task driven and case analysis, so that students can form a virtuous circle of theory practice theory to do their practice again. Theory teaching and practice teaching are closely combined to improve students' interest in learning, as well as their ability of practice and teamwork.

In order to achieve the teaching objectives of business intelligence course, different teaching methods are adopted in the teaching process according to different knowledge points and learning situations, including case teaching method, project driven teaching method, role-playing teaching method, group discussion teaching method and heuristic teaching method, so as to strengthen the communication between teachers and students, and give the main position to students on individual issues, Give full play to the initiative of students and stimulate their creativity.

\subsubsection{Teaching Implements}

\subsubsection{Using modern Educational Technology to Enrich the Effect of Teaching Scene}

Like all courses, this course also needs to use modern teaching methods to improve the classroom teaching effect, such as slides handout production, case short film broadcast, combination of network phenomena, etc., especially when explaining data mining technology, it needs to be combined with real cases to explain, and the analysis steps are segmented and detailed through live video, so that students can follow the teaching The teacher's ideas deepen the understanding of knowledge points. The use of these means enables students to learn while listening and to do while learning, realizing the integrated teaching mode of "teaching, learning and practice".

\subsubsection{Building Network Course Centre and Expanding Students' Learning Space}

Set up the website of business intelligence course center, and the teacher has formed such columns as course content explanation, key and difficult point analysis, exercise, assignment comment, course practice document standard, teaching discussion, online course Q \& A, etc. according to the content of lecture notes of course knowledge points, and timely enrich and adjust them according to the situation changes. At the same time, it also guides students to make use of Internet resources, find learning materials and cultivate selfstudy ability to make up for the limitations of classroom teaching.

\subsubsection{Construct Video Courseware of SPOC Class and Improve Students' Operation Level}

Record a video segment of the operation steps of business intelligence software. The video shows and explains the detailed steps of each function of the operation software, enabling students to quickly acquire the basic operation ability of business intelligence software, so as to understand the steps of business intelligence analysis and mining. Video can let students review each teaching unit of data mining course repeatedly after class, cultivate students to develop correct thinking mode and operation steps of data mining, and lay a good foundation for students to adapt to the needs of enterprises quickly.

\subsubsection{Improve Students' Self-Study Ability by \\ Combining Homework Answering with Tutoring}

In order to enable students to better master the course content and achieve the teaching purpose, homework, marking, answering questions and targeted guidance are essential links. This course is a large class. If students have problems in their normal study, they can solve the problems in their study by means of inter class answering, e-mail answering, course Center Forum or visiting the teacher's office at the appointed time. The teacher shall organize the common problems of 
students' questions in time and explain them uniformly in the class. In the team practice, teachers should grasp the progress in time, solve the problems in each stage, and ensure the effectiveness and accuracy of students' completion of the project.

\subsubsection{Integrate Ideological and Political Content into the Curriculum}

Business intelligence is a comprehensive course integrating multiple disciplines. There are many knowledge points in the teaching process that can be integrated into the key and difficult points of understanding and mastering the course. The proper combination of business intelligence knowledge and ideological and political education content can not only enrich the content of the course, but also make the course more in-depth, so that the teaching finally returns to the true purpose of "educating people".

The above five teaching methods combined with rich teaching methods will further improve the daily teaching of this course.

\section{SOLUTION}

SOPC New teaching modes and methods such as hybrid teaching have changed the thinking and methods of traditional teaching. The guiding ideology of students as the main body determines that these new teaching modes cannot be simply copied in the actual teaching process. Instead, we should start from the actual situation, adjust the teaching objectives and contents from the individual differences of students and online teaching, and adopt differentiated teaching strategies To provide students with more suitable learning paths and processes, and selective learning. Through SOPC based It can help teachers to change from knowledge imparter to learning director and promoter. It can help students to learn autonomously by using reasonable teaching strategy and perfect SPOC platform. At the same time, it can constantly improve the comprehensive value of teachers in information technology environment For students, it can enhance their interest in learning, change their attitude towards learning, cultivate their initiative in learning, and improve their ability to analyse and solve problems. The deepening development of SOPC teaching mode brings better learning experience for students, enables students to become the subject of learning, and cultivates high-quality talents needed by the current social development.

\section{REFERENCES}

[1] E.M. Clarke, E.A. Emerson, Design and synthesis of synchronization skeletons using branching time temporal logic, in: D. Kozen (Eds.), Workshop on Logics of Programs, Lecture Notes in Computer Science, vol. 131, Springer, Berlin, Heidelberg,
1981, pp. 52-71. DOI: https://doi.org/10.1007/BFb0025774

[2] J.P. Queille, J. Sifakis, Specification and verification of concurrent systems in CESAR, in: M. Dezani-Ciancaglini and U. Montanari (Eds.), Proceedings of the 5th International Symposium on Programming, Lecture Notes in Computer Science, vol. 137, Springer, Berlin, Heidelberg, 1982, pp. 337-351. DOI: https://doi.org/10.1007/3-54011494-7_22

[3] C. Baier, J-P. Katoen, Principles of Model Checking, MIT Press, 2008.

[4] M. Kwiatkowska, G. Norman, D. Parker, Stochastic model checking, in: M. Bernardo, J. Hillston (Eds.), Proceedings of the Formal Methods for the Design of Computer, Communication and Software Systems: Performance Evaluation (SFM), Springer, Berlin, Heidelberg, 2007, pp. 220-270. DOI: https://doi.org/10.1007/978-3-540-72522-0_6

[5] V. Forejt, M. Kwiatkowska, G. Norman, D. Parker, Automated verification techniques for probabilistic systems, in: M. Bernardo, V. Issarny (Eds.), Proceedings of the Formal Methods for Eternal Networked Software Systems (SFM), Springer, Berlin, Heidelberg, 2011, pp. 53-113. DOI: https://doi.org/10.1007/978-3-642-21455-4_3

[6] G.D. Penna, B. Intrigila, I. Melatti, E. Tronci, M.V. Zilli, Bounded probabilistic model checking with the muralpha verifier, in: A.J. Hu, A.K. Martin (Eds.), Proceedings of the Formal Methods in Computer-Aided Design, Springer, Berlin, Heidelberg, 2004, pp. 214-229. DOI: https://doi.org/10.1007/978-3-540-30494-4_16

[7] E. Clarke, O. Grumberg, S. Jha, et al., Counterexample-guided abstraction refinement, in: E.A. Emerson, A.P. Sistla (Eds.), Computer Aided Verification, Springer, Berlin, Heidelberg, 2000, pp. 154-169. DOI: https://doi.org/10.1007/10722167_15

[8] H. Barringer, R. Kuiper, A. Pnueli, Now you may compose temporal logic specifications, in: Proceedings of the Sixteenth Annual ACM Symposium on the Theory of Computing (STOC), ACM, 1984, pp. 51-63. DOI: https://doi.org/10.1145/800057.808665 
[9] A. Pnueli, In transition from global to modular temporal reasoning about programs, in: K.R. Apt (Ed.), Logics and Models of Concurrent Systems, Springer, Berlin, Heidelberg, 1984, pp. 123-144. DOI: https://doi.org/10.1007/978-3-642-82453-1_5

[10]B. Meyer, Applying "Design by Contract", Computer 25(10) (1992) 40-51. DOI: https://doi.org/10.1109/2.161279

[11] S. Bensalem, M. Bogza, A. Legay, T.H. Nguyen, J. Sifakis, R. Yan, Incremental component-based construction and verification using invariants, in: Proceedings of the Conference on Formal Methods in Computer Aided Design (FMCAD), IEEE Press, Piscataway, NJ, 2010, pp. 257-256.

[12]H. Barringer, C.S. Pasareanu, D. Giannakopolou, Proof rules for automated compositional verification through learning, in Proc. of the 2nd International Workshop on Specification and Verification of Component Based Systems, 2003.

[13] M.G. Bobaru, C.S. Pasareanu, D. Giannakopoulou, Automated assume-guarantee reasoning by abstraction refinement, in: A. Gupta, S. Malik (Eds.), Proceedings of the Computer Aided Verification, Springer, Berlin, Heidelberg, 2008, pp. 135-148. DOI: https://doi.org/10.1007/978-3540-70545-1_14 